\title{
Convocation Address 2015
}

\author{
Naveed A. Malik ${ }^{1}$
}

(May 2015, Virtual University, Pakistan)

It is my honor and pleasure to be given this opportunity to deliver the Convocation Address at the 27th General Convocation ceremony 2015 of the Open University of Sri Lanka. I have structured my talk around the potential of distance education and its relevance to the current job market. I will rely heavily on my experience with the Virtual University of Pakistan, but the thrust of my discourse should be applicable to the broader distance learning arena.

Distance education, as you all know, is not a new phenomenon. Over the years, the specific delivery methods and pedagogy have evolved and changed but the basic premise has remained the same: the provision of learning opportunities for knowledge seekers who faced one or more impediments in accessing formal education at conventional campuses. This issue of access to learning is assuming a much higher degree of importance in the current era, the primary reason being the changing face of the job market.

In previous years, the norm was to complete one's education in a certain field and then start one's career. By and large the starting and ending fields in the career remained the same. All that changed was one's level of experience and seniority and, therefore, responsibility. However, the current job market is very different. By and large, human endeavors have become much more interlinked and interdependent and specializing in a single discipline is no longer a recipe for success. Some minimum exposure or understanding of associated areas is necessary to become an effective contributor to the economic landscape. In earlier years one underwent continuous professional development or CPD to stay abreast of new developments, but this CPD was usually restricted to one's original basic field. The current requirements are quite different: CPD can mean anything ranging from staying abreast of new discoveries and developments in one's field, to complete retraining in an associated or even, in exceptional circumstances, a completely new field.

1 Correspondence should be addressed to Professor Dr. Naveed A. Malik, Virtual University of Pakistan, Pakistan. (Email: rector@vu.edu.pk) 
Conventional education systems are not geared to providing this type of education. They are usually limited by academic norms which are overly restrictive: age limits for induction into programs, the assumption of full time availability of students, workloads that cannot be managed while pursuing a career etc. However, distance education systems were designed ab-initio, to be flexible in nature and this is where their relevance to the current job market comes in.

Let us take a simple mono-disciplinary example. An essential component in architectural and engineering design is drafting. These professions have used skilled drafts-people for decades to create and present their design concepts. However, with the advent of computerized drafting tools, the productivity of drafts-people could be enhanced manifold through a simple re-training exercise. Along comes your university, the Open University of Sri Lanka which offers a Certificate in Computer Aided Drafting and Modeling using AutoCAD - the acknowledged king of the hill when it comes to Computer Aided Drafting. The very simple requirements for induction into the program read as follows:

1. Working knowledge of basic operation of a computer

2. Working knowledge of Draftsmanship / Drafting

\section{How much simpler could it get?}

While it is true that a conventional university could also offer this course (and many do), there are practical implications that only distance learning systems can address. One simple example of the limitations faced by institutions has to do with student numbers. A conventional institution will usually withdraw a course if the enrolment in the course is very low. Distance education does not suffer from this limitation. Since the course materials are predeveloped, the quantum of effort involved in offering a course is very small. Plus, a collection of learners from geographically disparate areas may still constitute a viable class cohort. This implies convenience for all learners who do not have to suffer dislocation, and convenience for the institution, that gets a reasonable class size.

The examples of re-training and lifelong learning opportunities that distance learning affords are innumerable and I will come back to this topic later. 
Let me now switch gears and address an aspect of distance learning that is very close to my heart - quality. When we started the Virtual University of Pakistan in 2002, one immediate obstacle that we had to face was the negative perception about distance learning. This was not restricted to Pakistan alone. People in general somehow thought that distance learning was not quite as good as conventional education. When we analyzed the issue, there were two objections that were voiced most frequently:

1. Courses in distance education are offered by nameless, faceless professors

2. One does not know who actually does the assignments and homework that constitute a significant fraction of the grade.

3. One does not know the identity of students appearing in an on-line examination.

The first issue was the easiest to tackle. The Virtual University of Pakistan had decided on a pedagogy that would be a mix of video lectures with online mentoring and support through a Learning Management System. We invited top-tier academics and professionals with well-known and recognizable names and faces, to develop our video lectures with the courses being designed with pain staking detail. These courses were then broadcast over free-to-air television and were viewable by the general public, not just the University's students. The top quality courses were quickly identified as the new face of distance learning and were very often cited by laypeople as exemplars of what a university course should look like. The first obstacle had been overcome. In a way, it was the "openness" of our contents that had won the day.

In the distance learning community, we are very aware of the effort that goes into the development of a new course and its associated materials. What the general public does not realize is that these courses are properly designed and developed, and in general, are far superior to the lectures delivered in conventional classrooms behind closed doors! We all need to get together and deliver this message vociferously.

As far as the second objection regarding the authorship of assignments is concerned, it is as applicable to a conventional institution as an institute of distance learning. However, it is more difficult to address for the general public. At the Virtual University of Pakistan, we have adopted a policy that ensures that no more than $15 \%$ of the grade for a course is determined by assignments and 
other semester work. $85 \%$ of the grade is determined through examinations.

This brings me to the third point. The Virtual University of Pakistan was designed as a technology based university with extensive reliance on Information and Communications Technologies or ICT. However, we decided that our examinations would be conducted in as conventional a manner as possible. Students have to appear for their examinations at designated exam centers, prove their identities to a University appointed invigilator and then sit for the exams under strict supervision. This system effectively removed the third objection.

The point I am trying to make is that graduates from distance learning institutions like the Open University of Sri Lanka, or the Virtual University of Pakistan are generally exposed to much higher quality courseware and assessed with as much rigor as any conventional institution. Add to this the fact that students in a distance environment are, in general, independent learners who are self-motivated and have to manage their time very carefully, and one concludes that their preparation for professional careers is actually much better than that of their counterparts from conventional institutions.

Coming back to the issue of life-long learning that now seems to be the requirement for the workforce of the future; we have new kids on the block in the form of Open Education Resources or OER and Massive Open Online Courses or MOOCs as they are popularly known.

As you all know, humankind's knowledge has now come to reside on the Internet. We no longer need physical access to knowledge repositories like libraries to obtain the information we need. Even the way we acquire information is changing and evolving as I speak. The search engines of the previous decade used to provide us links to thousands, if not millions, of pages that had some relationship to the term or terms we were searching for. It was our responsibility to sort out the search results and extract meaningful information from them. The search engines have themselves evolved over time.

For example, if we typed the question "Who killed Abraham Lincoln?" into Google, in previous years, it would come up with millions of pages that had references to Abraham Lincoln, and 
killing. Now it still returns 8.9 million results (correct as on May 2015) but it prefaces the results with a simple highlighted box that states "John Wilkes Booth". A much more sophisticated search engine, Wolfram Alpha, shows you how it interprets your query, and then provides the result which is "John Wilkes Booth", followed by some basic information such as his date and place of birth and date and place of death followed by an image, a timeline and some notable facts along with familial relationships! How is that for an answer from a computerized search engine!

But the story does not end here. When I visited University of Bradford in the UK several years ago, the Vice Chancellor pointed out that the familiar Google home page that used to be the starting point for browsers on student computers, had slowly but surely been replaced by Youtube! Why read when you can see? I put Youtube to the test all the way from Falafel recipes to changing the headlights on my car, and so far it has never failed me.

These examples simply illustrate how unstructured data can be mined to obtain useful information. When the data itself is structured and designed for a purpose, the value of such queries is multiplied manifold. This is the realm of OER. As the Internet, especially YouTube, has amply demonstrated, people like to share knowledge. Open Education Resources are no different: they are simply a means for domain experts to share their expertise with knowledge seekers across the globe. Since they are designed as knowledge objects, their worth in a continuously changing education and training landscape is very high. Learners can quickly access specific topics of their interest and quickly acquire skills that would otherwise not have been possible. An academic use of OER is the repurposing and re-combination of OER into larger knowledge offerings, typically in the form of new courses. The domain is very rich and a considerable amount of work is happening in this area. This re-purposing and re-combination of OER is particularly relevant to distance learning systems, especially systems that have a strong reliance on modern ICT channels.

When juxtaposed against the requirements of lifelong learning, the value of OER immediately become apparent. Knowledge seekers no longer have to dive into a mountain of data to find the nuggets they need. Someone somewhere has already created the nuggets and placed them ready for easy access in the form of OER or in the case 
of distance learning universities, created a full-fledged course using OER that carries formal academic credit.

The other major intervention that is being seen and experienced in the on-line learning landscape is the advent of Massive Open Online Courses or MOOCs. Started as an experiment in collaborative learning, MOOCs have made rapid progress since then and a huge amount of learning has happened in the process. One of the early realizations was the fact that students had very limited attention spans when exposed to video lectures. The analysis of video offerings indicated that student attention spans were limited to about 4 to 6 minutes after which they closed the video. This number was independent of the length of the original video recording.

We have taken this lesson to heart at the Virtual University of Pakistan. Our current format for courses that are now being developed reflects this finding. Courses no longer comprise a series of 1-hour video lectures; they now consist of a collection of video topics with each topic being limited to about five minutes each. Needless to say, this limit is not absolute, but offering short, concise coverage of topics seem more in consonance with today's learners with a short attention span.

A side benefit of this new format is that instead of wondering in which lecture a particular topic is covered, students can directly locate the topic in the course and study or review it as the case may be. The topic based format also allows flexibility in the way in which students traverse a particular course and is especially relevant for non-formal life-long learners. Of course, the fact that the Virtual University of Pakistan subscribes to the openness concept helps: all of our courses are published in the form of open courseware or OCW and available completely free of cost to all visitors to the University's OCW site.

Distance Learning is assuming a position of great importance for tertiary education, primarily because of the changing nature of the job market. Even major, top-tier conventional institutions such as MIT and Stanford have ventured into distance education by their contributions in the form of Open Courseware and MOOCs both of which fall into the general category of OER. The transformation of MOOCs into for-credit courses that are acceptable to the wider academic community is a major step forward and the possibility of these efforts becoming part of the educational mainstream does not 
seem too far-fetched. In fact, envisioning a future of tertiary education and training that is not impacted by the advent of OER and MOOCs seems more and more unlikely.

I hope this talk has not been too boring. The important lessons that I would like you to carry with you as you graduate are as follows: you are the beneficiaries of a very high quality education system and the learning acquired here at the Open University of Sri Lanka shall stand you in good stead in the days to come. Of course, you have acquired skills other than your course contents as well: you are independent learners; you manage your time effectively; you are able to seek knowledge and information as and when you need it, and most of all, you have benefited from a system that expands access to higher education and by keeping it affordable, makes this access equitable as well.

Let me end by my talk with the same words that I used at our recent convocation at the Virtual University: Let your future actions be founded on honesty, integrity, dedication and a sense of purpose. Be true to yourself and pursue careers of your liking and interest. I am confident that the knowledge and training gained here at the Open University of Sri Lanka will hold you in good stead wherever the future leads you. Remember: attaining a degree is not the end of your learning pathways. You should continuously be learning and adding to your knowledge and skills. You should have the courage to follow your heart and give your best to everything that you do.

Congratulations \& Thank you! 